\section{En memoria al Prof. Dr. Mario Julio Avila Campos}

\section{In memory of Prof. Dr. Mario Julio Avila Campos}

\section{En Memoria}

\author{
Donald Ramos Perfecto ${ }^{1, a}$, Hilda Moromi Nakata ${ }^{1, b}$ \\ ${ }^{1}$ Universidad Nacional Mayor de San Marcos, Facultad de \\ Odontología, Lima, Perú. \\ ${ }^{a}$ Doctor en Estomatología.

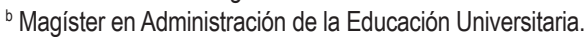

\section{Correspondencia:}

Donald Ramos Perfecto

Correo electrónico: dramosp@unmsm.edu.pe

Universidad Nacional Mayor de San Marcos, Facultad de Odontología. Calle Germán Amézaga 375. Lima 1, Perú.

Recibido: 09/07/19
Aceptado: 18/07/19
Publicado: 12/09/19
El Dr. Mario Julio Avila Campos, falleció el 28 de abril del 2019 en Sao Paulo, Brasil, hombre estudioso dedicado a conocer la microbiología anaerobia bucal, dejando múltiples investigaciones que sirvieron de base para otras, así como los conocimientos que nos permitió comprender mejor la fisiopatología de muchas bacterias periodontopatógenas. Su laboratorio de anaerobios del Instituto de Ciencias Biomédicas de la Universidad de Sao Paulo (ICB-USP) donde laboró hasta sus últimos días, pudo recibir a muchos estudiantes de pre y posgrado de diferentes nacionalidades, entre ellos peruanos que se formaron allí, teniendo apoyo para el desarrollo de sus proyectos de investigación.

El Dr. Avila Campos, nació el 5 de abril de 1957, en el distrito de la Victoria, hizo sus estudios de primaria y secundaria en el colegio Gimnasio Peruano de Lince, licenciándose en Ciencias Biológicas en la Universidad Particular Ricardo Palma (1980), siendo una de sus primeras labores como docente, ser parte del grupo de profesores del entonces departamento de Microbiología con sede en la Facultad de Odontología de la Universidad Nacional Mayor de San Marcos, en ese tiempo dirigido por el Dr. Alfonso Nicho Temoche pionero de la enseñanza de la Microbiología bucal en el país.

Como integrante del equipo docente permanente tuve la oportunidad de conocer y compartir las tareas en el aula, su don de gente, su amabilidad, así como el deseo de superación constante era su característica. Siempre colaborador y entusiasta, recordando cuando como coordinador del Dpto. de Ciencias Básicas lo invitamos a compartir sus experiencias en nuestra Facultad de Odontología, con mucho gusto accedió y como Direc- tora de la Revista Odontología Sanmarquina en el año 2010, lo invité a formar parte del comité consultivo, accediendo gustoso, colaboración que cumplió hasta la fecha de su deceso, Q.E.P.D (HMN).

En su deseo por querer aprender y perfeccionarse, obtuvo una beca para seguir estudios de una Maestría en Ciencias Biológicas-Microbiología (1986) en la Universidad Federal de Minas Gerais, defendiendo su tesis titulada: Actinobacillus actinomycetemcomitans: aspectos ecológicos, fisiopatológicos y de susceptibilidad a antimicrobianos. Su estudio de Doctorado en Ciencia - Microbiología (1991) lo realizó en la Universidad Federal de Rio de Janeiro. Así también realizó estudios posdoctorales en el Centro para el Control y Prevención de Enfermedades (CDC) en Atlanta, USA y en la Universidad de California, USA. Desde 1991 hasta el 2019 estuvo como docente responsable del laboratorio de anaerobios del ICB-USP.

En su producción científica se suma más de cien artículos publicados en revistas de gran impacto como: Journal of Periodontology, Brazilian Journal of Microbiology, Journal of Applied Oral Science, Canadian Journal of Microbiology, Oral Diseases, Anaerobe, entre otras. Sus estudios desarrollaban temas de microbiología odontológica, médica y veterinaria, poniendo gran énfasis en bacterias anaerobias de la cavidad bucal y del tracto intestinal, estudiando los factores de virulencia, resistencia antimicrobiana y análisis molecular de ellas. En relación a la cavidad bucal, estudió con mucho interés las bacterias periodontopatógenas como: Aggregatibacter actinomycetemcomitans, Porphyromonas gingivalis, Prevotella intermedia, Fusobacterium nucleatum, entre otras anaerobias. 
Una vida dedicada a la investigación y al conocer muy bien aquellos seres diminutos presentes en la cavidad bucal, causantes de patologías bucodentales. Tuve la oportunidad de hacer una pasantía en su laboratorio de anaerobios del ICB-USP, integrándome a un equipo donde habían peruanos que estaban realizando su doctorado, siempre tuvo la visión y el deseo de que más compatriotas aprendieran y se educaran en su laboratorio, su desprendimiento de dar todo lo que había apren- dido en tantos años, lo hacía un maestro en su especialidad (DRP).

El Dr. Mario Julio Avila Campos, partió, pero su legado dejado en un principio en el Perú y luego en el Brasil, así como en sus estudiantes de pre y posgrado que pasaron por sus manos como docente, sus investigaciones y mucho más su don de persona, hacen que su partida sea sentida y su presencia muy extrañada. ¡Que Dios guarde a usted!

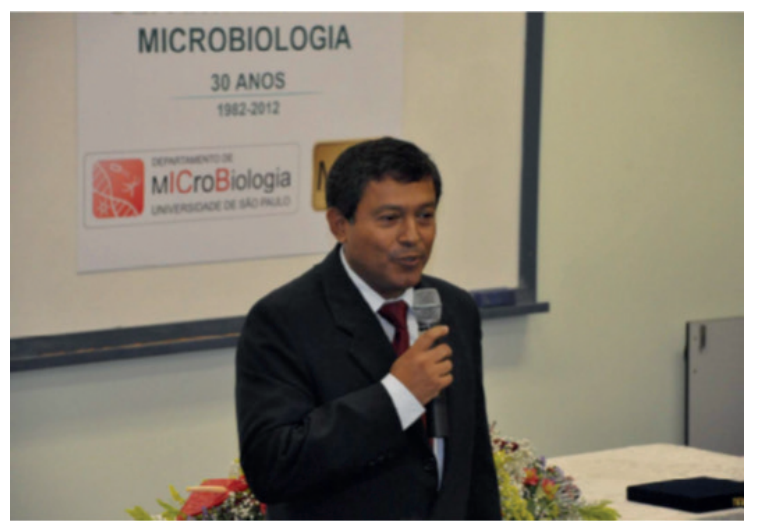

Dr. Mario Julio Avila Campos como jefe del departamento de Microbiología del Instituto de Ciencias Biomédicas de la Universidad de Sao Paulo - Brasil

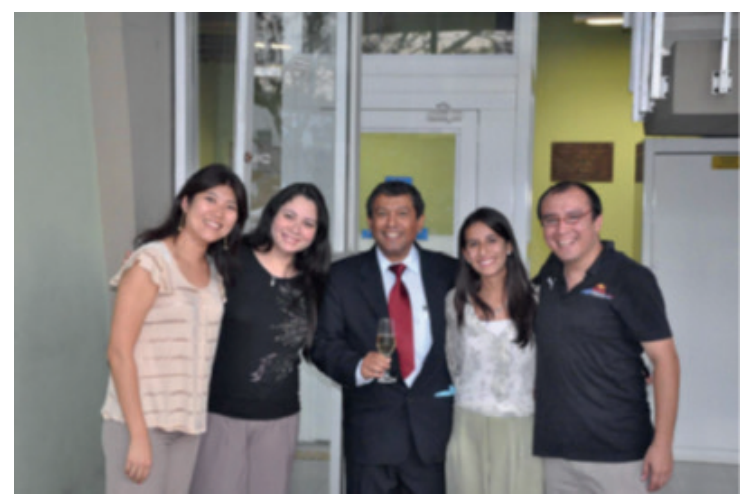

El Dr. Mario Julio Avila Campos en el centro, con sus alumnos y colaboradores del laboratorio de Anaerobios del Instituto de Ciencias Biomédicas

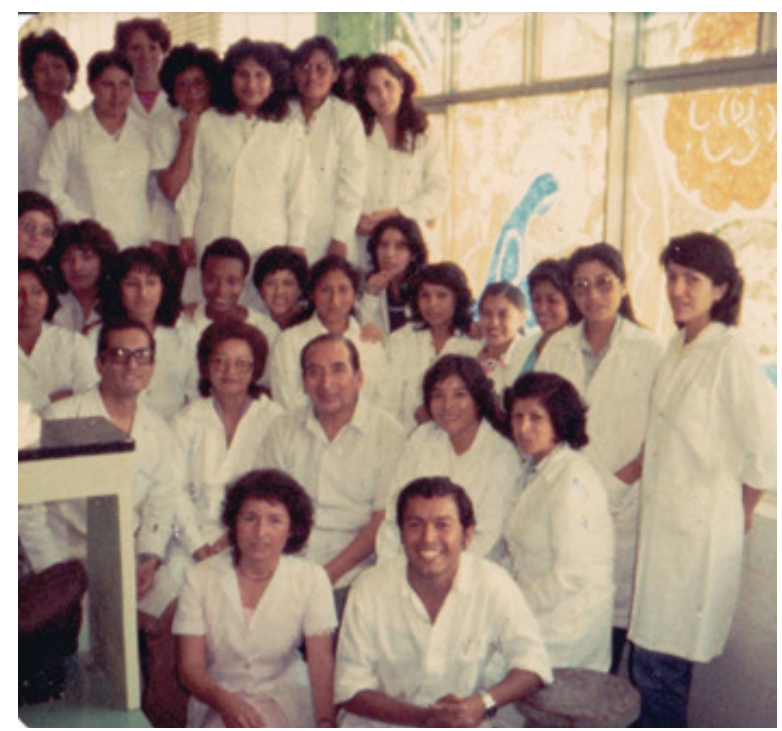

El Doctor Mario Avila Campos, en primera fila, con docentes de la Facultad de Odontología y estudiantes de la Asignatura de Microbiología, en la Ciudad Universitaria de la Universidad Nacional Mayor de San Marcos, 1983. 